\title{
O Movimento Antimanicomial como sujeito coletivo de direito
}

The Anti-asylum Movement as a collective subject of law

\section{Ludmila Cerqueira Correia ${ }^{1}$}

1 Universidade Federal da Paraíba, João Pessoa, Paraíba, Brasil. E-mail: ludcorreiaufpb@gmail.com. ORCID: https://orcid.org/0000-0001-5721-4032.

José Geraldo de Sousa Junior²

2 Universidade de Brasília, Brasília, Distrito Federal, Brasil. E-mail: jgsousa@terra.com.br. ORCID: https://orcid.org/0000-0002-8974-2283.

Artigo recebido em 27/12/2018 e aceito em 16/09/2019.

\section{$(\mathrm{cc}) \mathrm{EY}$}

This work is licensed under a Creative Commons Attribution 4.0 International License. 


\section{Resumo}

Este artigo objetiva analisar a configuração do Movimento Antimanicomial enquanto sujeito coletivo de direito, refletindo sobre a sua atuação e a sua capacidade de reivindicar e enunciar direitos, a partir do marco teórico de O Direito Achado na Rua. Considerando as noções de protagonismo e empoderamento no contexto das pessoas loucas, também aborda a centralidade da participação destas no Movimento a partir das suas próprias experiências.

Palavras-chave: Movimento Antimanicomial; Sujeito coletivo de direito; O Direito Achado na Rua.

\section{Abstract}

This article aims to analyze the configuration of the Anti-asylum Movement as a collective subject of law, reflecting on its performance and its ability to claim and enunciate rights, based on the theoretical framework of The Right Found in the Street. Considering the notions of protagonism and empowerment in the context of crazy people, it also addresses the centrality of their participation in the Movement from their own experiences.

Keywords: Anti-asylum Movement; Collective subject of law; The Right Found in the Street. 


\begin{abstract}
“O manicômio é expressão de uma estrutura, presente nos diversos mecanismos de opressão desse tipo de sociedade. A opressão nas fábricas, nas instituições de adolescentes, nos cárceres, a discriminação contra negros, homossexuais, índios, mulheres. Lutar pelos direitos de cidadania dos doentes mentais significa incorporar-se à luta de todos os trabalhadores por seus direitos mínimos à saúde, justiça e melhores condições de vida." (Trecho do Manifesto de Bauru, 1987)

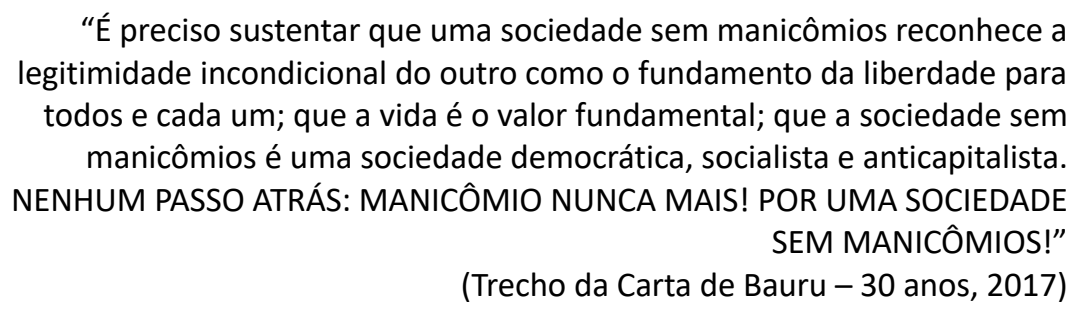

Introdução

Este artigo baseia-se em resultados da pesquisa de doutorado desenvolvida no Programa de Pós-graduação em Direito da Universidade de Brasília ${ }^{1}$. Portanto, o estudo integra uma pesquisa mais ampla, que teve como objetivo principal analisar as experiências de assessoria jurídica popular universitária em direitos humanos e saúde mental no Brasil, na perspectiva do acesso ao direito e à justiça. A partir da leitura e análise de artigos, livros e teses que tratam sobre diversos aspectos da luta antimanicomial no Brasil, pretende-se trazer as reflexões sobre a configuração do Movimento Antimanicomial enquanto um sujeito coletivo de direito, na perspectiva de O Direito Achado na Rua.

A discussão sobre a violência, os aspectos da exclusão, a privação da liberdade, os maus tratos, as práticas de tortura e todas as ordens de abuso de poder nos manicômios brasileiros foi propulsora do Movimento Nacional da Luta Antimanicomial (MNLA), ator fundamental para as reflexões acerca da dimensão jurídico-política da Reforma Psiquiátrica brasileira. Tal Movimento se originou do Movimento dos Trabalhadores em Saúde Mental (MTSM), com o processo de redemocratização do país, durante as mobilizações contra a ditadura civil-militar que reuniam movimentos populares oriundos da sociedade civil que se organizavam e lutavam para ampliar a participação política na esfera pública.

\footnotetext{
1 Esta pesquisa, concluída em 2018, obteve financiamento da CAPES, através do Programa de Doutorado
} Sanduíche no Exterior (PDSE). 
Em meados da década de 1970, além de reivindicar melhores condições de trabalho nos manicômios do país, a ampliação do número de funcionários e o aumento dos investimentos do setor público na área da saúde mental, o MTSM passou a denunciar as violações de direitos civis de pessoas internadas nos hospitais e clínicas psiquiátricas e o modelo privatizante e hospitalocêntrico adotado pelo estado brasileiro (AMARANTE, 1997, 1998). Em 1978, o MSTM é organizado como movimento nacional e com o objetivo de constituir-se em "espaço de luta não institucional, em lugar de debate e onde se encaminham as propostas de transformação da assistência psiquiátrica, que aglutina informações, organiza encontros, reúne trabalhadores da saúde, associações de classe", além de amplos setores da sociedade (AMARANTE, 1998, p. 60). Nesse sentido, Amarante (1998) destaca o MTSM como um movimento de luta popular engajado no campo da saúde mental.

É preciso ressaltar que o MTSM não estava dissociado do Movimento da Reforma Sanitária, o que pode ser observado a partir da sua luta pela necessária democratização na área da saúde para reorganização da assistência em saúde mental. Daí a importância de outro ator nesse processo, o Centro Brasileiro de Estudos de Saúde (CEBES) que, em outubro de 1979, apresentou o documento “A Questão Democrática na Área da Saúde" no I Simpósio sobre Política Nacional de Saúde na Câmara dos Deputados (CAMARGO et al., 2016). O texto desse documento alinhavava as diretrizes fundamentais que apontavam para "uma saúde autenticamente democrática": a saúde como direito; criação de um Sistema Único de Saúde com a responsabilidade do Estado e a descentralização (CAMARGO et al., 2016, p. 13).

Além disso, o MTSM tinha como referência principal o movimento da Psiquiatria Democrática, liderado por Franco Basaglia na Itália, que efetivou a ruptura com o hospital psiquiátrico, substituindo o modelo asilar/carcerário por uma rede diversificada de serviços de atenção diária em saúde mental de base territorial e comunitária (BASAGLIA, 1982). Vale frisar que Franco Basaglia esteve no Brasil nos meses de junho e julho de 1979, participando de conferências e debates realizados em São Paulo, Rio de Janeiro e Belo Horizonte. Durante esse período, ele manteve contato com integrantes do MTSM, fortalecendo ainda mais as reivindicações do movimento e abrindo um novo campo de reflexões (BASAGLIA, 1979). As suas conferências influenciaram profundamente as pessoas que delas participaram e os percursos no projeto de mudança das instituições psiquiátricas brasileiras (AMARANTE, 1998; NICÁCIO; 
AMARANTE; BARROS, 2000; FERNANDES; SCARCELLI, 2005).

O Movimento Nacional da Luta Antimanicomial (MNLA) nasceu em dezembro de 1987, após a I Conferência Nacional de Saúde Mental (junho/1987), no II Congresso Nacional dos Trabalhadores em Saúde Mental, realizado em Bauru - SP, com o lema "Por uma sociedade sem manicômios", que exigia que os hospitais psiquiátricos fossem substituídos por outras formas de tratamento, capazes de garantir a dignidade e a liberdade das pessoas em sofrimento mental, com base nos seus direitos (AMARANTE, 1997, 1998). Naquele momento, com o Manifesto de Bauru, documento da fundação do MNLA, este é identificado enquanto movimento social, como veio a se confirmar no I Encontro Nacional da Luta Antimanicomial realizado em Salvador-BA, no ano de 1993, com o lema "O Movimento Antimanicomial como movimento social" (BARBOSA; COSTA; MORENO, 2012).

Ao enfatizar que as ações e lutas do Movimento Antimanicomial estão direcionadas e impactando as diferentes dimensões da vida social, Luchmann e Rodrigues (2007) o reafirmam como um movimento social importante na sociedade brasileira, uma vez que se organiza e se articula para transformar as condições, relações e representações acerca da loucura na sociedade. Desse modo, o MNLA passou a contribuir para a reconstrução da relação da sociedade com a louca e a loucura, visando a superação do estigma e da desqualificação das loucas e loucos² ${ }^{2}$ Mais adiante, o Movimento iniciou a discussão sobre a necessidade de uma Reforma Psiquiátrica no país, na perspectiva da garantia dos direitos humanos das pessoas em sofrimento mental.

Embora se reconheça, atualmente, a existência de vários grupos oriundos do MNLA, sobretudo após as divergências e embates no início dos anos 2000, não é objetivo deste artigo discutir as cisões e as novas correntes e organizações surgidas nesse percurso histórico - MNLA, RENILA - Rede Nacional Internúcleos da Luta Antimanicomial, associações de usuários e familiares etc (BARBOSA; COSTA; MORENO, 2012; VASCONCELOS, 2010, 2012). No bojo dessa discussão está a discordância radical

\footnotetext{
2 Embora haja uma série de denominações para se referir às pessoas psiquiatrizadas ou com diagnóstico de transtorno mental (contidas em documentos legais ou publicações científicas), para este artigo foi escolhido o termo "loucas e loucos", pois é a denominação pela qual as loucas e loucos que militam numa associação na qual a autora realizou assessoria jurídica preferiam ser chamados, por identificarem-se politicamente com ela. E adotou-se a palavra louco nos gêneros feminino e masculino como forma de propor linguagem crítica e inclusiva de gênero. Para as demais palavras no texto, optou-se por não fazer uso dos marcadores de gênero (as/os), adotando o gênero feminino em todo o texto, na busca pela desconstrução do uso sexista da linguagem que considera o gênero masculino como universal (BANDEIRA, 2008; OLIVEIRA; DUQUE; WEYL, 2012).
} 
entre grupos diversos no que diz respeito à autonomização e à institucionalização do Movimento (VASCONCELOS, 2012, 2016). Como explicita Vasconcelos (2016, p. 94), a divisão dessas correntes tem bases geográficas definidas, praticamente inexistindo a corrente oposta em cada um dos estados, e além disso, tal autor aponta que a RENILA "polariza a maior parte das associações, núcleos e fóruns estaduais", ficando o MNLA restrito aos ativistas, grupos e coletivos de apenas dois estados.

É importante fazer esse registro, uma vez que isso faz parte da caracterização de um movimento social popular com tamanha amplitude e inserção na luta por políticas públicas de saúde inclusivas, e, sobretudo, com a participação de atores diversos, com destaque para as loucas e loucos. Corrobora, ainda, a análise de Vasconcelos (2016, p. 93), que, ao pesquisar os núcleos e coletivos de militância do Movimento Antimanicomial, refere-se aos mesmos como "conjunto do movimento", concluindo pela existência de um "movimento antimanicomial" no país.

Sendo assim, neste artigo adota-se a denominação Movimento Antimanicomial (MA) para se referir ao conjunto de grupos, organizações, núcleos, frentes e coletivos da sociedade civil que têm lutado por uma Reforma Psiquiátrica antimanicomial no Brasil, ou seja, que reivindicam políticas públicas de saúde mental garantidoras de direitos e baseadas num modelo comunitário e territorial. Esta escolha baseia-se, ainda na organização do "Encontro de Bauru: 30 anos por uma sociedade sem manicômios", realizado em dezembro de 2017 em Bauru-SP, que teve a participação dos diversos segmentos que compõem o Movimento Antimanicomial, articulados num coletivo amplo que constituiu a "Articulação Nacional Pró Encontro Bauru: 30 anos de luta por uma sociedade sem manicômios" ${ }^{3}$.

Este artigo tem como objetivo analisar se o Movimento Antimanicomial se constitui como sujeito coletivo de direito e alguns elementos da sua mobilização políticojurídica para salvaguardar as conquistas sociais e os direitos por ele realizados em face de ameaças e de mudanças que têm sido implementadas nas políticas de saúde mental no Brasil. Para tanto, a partir de uma pesquisa bibliográfica (livros, capítulos de livros, artigos e teses), traz aspectos históricos da criação desse movimento, com destaque para a significativa participação das pessoas loucas, na perspectiva do marco teórico de 0 Direito Achado na Rua, sobretudo com as formulações de Roberto Lyra Filho e José

\footnotetext{
${ }^{3}$ Relatório final do Encontro disponível em: <https://site.cfp.org.br/wp-content/uploads/2018/11/relatorioencontro-de-bauru-1.pdf>. Acesso em: 20 ago. 2019.
} 
Geraldo de Sousa Junior (COSTA et al., 2008).

Ao dedicar-se à superação das ideologias jurídicas hegemônicas, Roberto Lyra Filho (1982, p. 86) desconstrói as falsas imagens sobre o direito, e, assim, faz críticas ao jusnaturalismo e ao positivismo jurídico, afirmando o direito como processo dentro do processo histórico: "não é uma coisa feita, perfeita e acabada; é aquele vir-a-ser que se enriquece nos movimentos de libertação das classes e grupos ascendentes e que definha nas explorações e opressões que o contradizem, mas de cujas contradições, brotarão as novas conquistas.". Para este autor, o direito "se apresenta como positivação da liberdade conscientizada e conquistada nas lutas sociais e formula os princípios supremos da Justiça Social que nelas se desvenda." (LYRA FILHO, 1982, p. 88).

O direito é compreendido, portanto, na realidade social, a partir das relações de poder, como processo histórico de lutas por dignidade e libertação, para além das questões normativas, mas sem ignorá-las para a constituição do direito, seja de uma perspectiva de opressão ou de positivação da liberdade conscientizada. Um direito que se expressa como ontologia dialética do ser social, como afirma Lyra Filho (1982, p. 12):

Nesta perspectiva, quando buscamos o que o Direito é, estamos antes perguntando o que ele vem a ser, nas transformações incessantes do seu conteúdo e forma de manifestação concreta dentro do mundo histórico e social. Isto não significa, porém, que é impossível determinar a "essência" do Direito - o que, apesar de tudo, ele é, enquanto vai sendo: o que surge de constante, na diversidade, e que se denomina, tecnicamente, ontologia. Apenas fica ressalvado que uma ontologia dialética, tal como indicava o filósofo húngaro, Lukács, tem base nos fenômenos e é a partir deles que procura deduzir o "ser" de alguma coisa, buscado, assim, no interior da própria cadeia de transformações.

Desse modo, para O Direito Achado na Rua, a norma não é considerada sinônimo do direito, ou seja, o direito não se reduz à norma e pode, inclusive, estar fora dela ou até mesmo ser contrário a ela, e, assim, enfatiza a "transição da visão substantiva do direito para uma percepção processual, institucional e organizacional do direito, operando um deslocamento da unidade de análise centrada na norma para uma unidade de análise centrada no conflito." (SOUSA JUNIOR, 2008, p. 224).

Movimento Antimanicomial: sujeito coletivo de direito?

É no Congresso de Bauru que se observa uma renovação política do MTSM, ao se 
aproximar das organizações de usuárias e familiares que passam a participar das discussões do Movimento, havendo, portanto, a significativa inserção das usuárias dos serviços de saúde mental e das suas familiares no Movimento Antimanicomial (LUCHMANN; RODRIGUES, 2007). Como salienta Nabuco (2008, p. 82), a partir daí diversos usuários e familiares têm denunciado a violência nos manicômios, tornando-se "lideranças assumindo papéis estratégicos em Conselhos Municipais e Estaduais de Saúde, na Comissão Intersetorial de Saúde Mental do Conselho Nacional de Saúde, nos Encontros da Luta Antimanicomial e nos Encontros de Usuários e Familiares da Luta Antimanicomial.".

Outro marco foi o III Encontro Nacional de Usuários e Familiares, realizado em 1993, em Santos - SP, no qual foi redigida a "Carta de direitos e deveres dos usuários e familiares de serviços de saúde mental". Yasui (2010, p. 61) analisa que, em geral, o texto dessa Carta não traz novidades em relação a outros documentos a ela contemporâneos, mas aponta como novidade o processo de sua elaboração, pois foi um texto discutido e debatido pelos usuários e familiares: "O louco, destituído de sua condição de cidadão, afirma-se como sujeito de seu tempo e escreve, literalmente, uma página de sua história.".

Vale a pena frisar que diversas autoras na área da saúde mental problematizam a questão da cidadania da louca, afirmando que o universo da loucura se inscreveu de maneira estranha na ordem política com a criação do Estado Moderno, excluindo as loucas do estatuto de cidadania plena e do reconhecimento dos seus direitos fundamentais (DELGADO, 1992; COSTA; TUNDIS, 2001; SOALHEIRO, 2003).

Como a loucura passou a ser associada à ausência de razão (BASAGLIA; BASAGLIA, 1971), a louca não era considerada como igual às demais cidadãs, e, portanto, "como um ser mutilado na sua razão, o louco não poderia exercer a sua vontade e ter discernimento para se apropriar legitimamente de sua liberdade [...], não podendo consequentemente ser representado como um sujeito do contrato social." (BIRMAN, 1992, p. 74). E no contexto do modelo hospitalocêntrico, com a predominância do discurso psiquiátrico, observa-se a "produção de uma ordem social asilada pela psiquiatria, onde essa regularia a produção da cidadania." (BIRMAN, 1992, p. 86).

Conforme Silva (2007, p. 2), "A efetivação da cidadania foi o principal alicerce de todas as reivindicações dos movimentos e agentes sociais que lutaram pela transformação da assistência em saúde mental no Brasil.". Trata-se de uma discussão que 
permanece atual nessa área, mesmo com as mudanças já produzidas pela Reforma Psiquiátrica, iniciada no final da década de 1980. A Reforma Psiquiátrica brasileira é identificada como um processo complexo, com quatro dimensões: teórico-conceitual, técnico-assistencial, jurídico-política e sociocultural (AMARANTE, 2017). Na sua implementação, passou a realizar práticas para efetivar a desinstitucionalização, promovendo o fortalecimento de serviços substitutivos ao hospital psiquiátrico, inseridos no contexto descentralizado do Sistema Único de Saúde, a partir da estruturação de uma rede de serviços de atenção diária em saúde mental de base territorial (ROTELLI, 2001; AMARANTE, 2017).

O debate acerca do reconhecimento da cidadania da louca vai reverberar, portanto, na possibilidade de sua participação na vida social, com destaque para os processos de organização, mobilização e reivindicação de direitos. Nesse sentido, Pedro Delgado (2011) destaca a entrada em cena das loucas e loucos como sujeitos políticos ${ }^{4}$, ao afirmar que é necessário introduzir um novo personagem na história, que, segundo ele, deveria estar presente desde o início, mas que só teve a possibilidade de fato de entrar na cena da política quando um projeto de lei que tinha a proposta de reformular a assistência psiquiátrica foi apresentado ao legislativo brasileiro. "Não existia o paciente, como sujeito político. Tudo se fazia em nome dele, para seu bem, sempre o que parecia ser o melhor para ele. Mas ele nunca estava presente para dizer o que pensava a respeito." (DELGADO, 2011, p. 116).

Aqui encontra-se uma das questões essenciais para se refletir sobre a configuração do Movimento Antimanicomial (MA) no Brasil e suas características. Sendo assim, toma-se a categoria "sujeito coletivo de direito", uma das categorias da concepção do direito como liberdade (LYRA FILHO, 1982; SOUSA JUNIOR, 2008), para problematizar como se constitui o sujeito coletivo na luta antimanicomial e qual o papel das loucas e loucos no processo de constituição e consolidação do MA e nas suas transformações e rupturas, destacando as suas peculiaridades. O objetivo, portanto, é identificar se o MA se configura ou não como sujeito coletivo de direito, tendo em vista os seus principais componentes e características.

Foi o MA que impulsionou a elaboração de propostas visando a transformação da assistência psiquiátrica no Brasil, iniciando a crítica da psiquiatria como prática de

\footnotetext{
${ }^{4}$ Isso ocorre no final dos anos 80, sobretudo com a participação dessas pessoas através das associações de
} usuários e familiares (YASUI, 2010; VASCONCELOS, 2016). 
controle e reprodução das desigualdades sociais e o debate sobre a desinstitucionalização. Com a participação de trabalhadoras, usuárias dos serviços de saúde mental e de suas familiares, bem como de jornalistas, artistas, estudantes e intelectuais, o MA pautou a necessidade de transformações no modelo de atenção em saúde mental oferecido no país e organizou sua estrutura administrativa como fórum nacional, congregando várias entidades, como Organizações Não Governamentais (ONGs) e associações de usuárias e familiares. Ao longo dos seus trinta anos de existência, os diversos grupos e núcleos criados nos estados se mobilizaram para a elaboração e aprovação de leis estaduais de Reforma Psiquiátrica (PEREIRA, 2004; VASCONCELOS, 2016).

De acordo com Luchmann e Rodrigues (2007, p. 406), o Movimento Antimanicomial

é uma ação coletiva cuja orientação comporta solidariedade, manifesta conflitos e implica a ruptura dos limites de compatibilidade do sistema de saúde mental no país. A configuração dos atores e instituições (trabalhadores, profissionais, políticos, empresários, usuários e familiares) conforma um quadro multipolar deste campo que, embora atravessado por diversos conflitos e ambigüidades, vem promovendo alterações significativas nas quatro dimensões apontadas, quais sejam: epistemológica, técnicoassistencial, político-jurídica e sociocultural.

Recorde-se que, em 1993, no I Encontro Nacional da Luta Antimanicomial, realizado em Salvador - BA, identificou-se a participação significativa das usuárias dos serviços, o que proporcionou a discussão sobre a necessidade de fortalecimento da organização política desse segmento (SOALHEIRO, 2003). Essa atuação das usuárias vai ganhar nova dimensão com a elaboração da "Carta sobre os direitos e deveres dos usuários e familiares dos serviços de saúde mental", no III Encontro Nacional de Usuários e Familiares, já citado acima, no qual tiveram relevância os debates sobre o reconhecimento da situação das loucas e loucos e os seus direitos.

Conforme ressalta Sousa Junior (2002, p. 89), “A análise sociológica pôde precisar que a emergência do sujeito coletivo pode operar um processo pelo qual a carência social contida na reivindicação dos movimentos é por eles percebida como negação de um direito, o que provoca uma luta para conquistá-lo.". Ainda de acordo com esse autor (SOUSA JUNIOR, 2008, p. 146),

A partir da constatação derivada dos estudos acerca dos chamados novos movimentos sociais, desenvolveu-se a percepção, primeiramente elaborada pela literatura sociológica, de que o conjunto das formas de mobilização e organização das classes populares e das configurações de classes 
constituídas nesses movimentos instaurava, efetivamente, práticas políticas novas em condições de abrir espaços sociais inéditos e de revelar novos atores na cena política capazes de criar direitos.

Sendo assim, passa-se a problematizar a configuração do Movimento Antimanicomial como sujeito coletivo, refletindo sobre a sua atuação e a sua capacidade de reivindicar e enunciar direitos.

Como observado acima, o MA nasce a partir da mobilização de trabalhadoras da saúde mental, em torno do MTSM, que se caracterizou por uma dupla finalidade: "a promoção da melhoria das condições de trabalho no âmbito da saúde mental e a humanização das relações sociais que envolvem as pessoas com transtornos mentais e, em última instância, das ações em saúde mental." (MUSSE, 2008, p. 70). Com a aproximação e inserção das usuárias e familiares no MA, percebem-se algumas divergências e conflitos, expressos nas diferenças de propostas no interior do movimento, como constatam Luchmann e Rodrigues (2007, p. 405): "A existência de três segmentos - usuários, familiares e profissionais - é um ingrediente importante no aumento da complexidade identitária e na formulação de interesses.". Evidenciam, ainda, as diferenças de recursos, de interesses e de poder entre tais segmentos, como é o caso da reivindicação de se reconhecer as características particulares de usuárias e familiares como atores políticos.

Ao confirmar a importância do MA, Nabuco (2008) destaca a resistência das usuárias no que diz respeito às relações de poder e, por isso, enfatiza a necessidade de dar visibilidade à luta destas e de como se constitui a sua participação política e a forma de dar encaminhamento a suas lutas. Essa é uma questão relevante para compreender o lugar das usuárias no MA e a luta por direitos por esse segmento que, em regra, historicamente, foi tratado como objeto do "saber psiquiátrico" (BASAGLIA, 1979).

A condição de sujeito de direitos está vinculada à ideia de titularidade de direitos. Esse debate é iniciado na área da saúde mental a partir do MA, que passa a discutir a condição de cidadania das loucas e loucos, conforme apontado acima (BIRMAN, 1992) e, como alerta Janaína Silva (2007, p. 57), essas pessoas não são simplesmente objeto de proteção, mas sujeitos que atuam na "definição das formas como o Direito regulará os aspectos de sua identidade passíveis de normatização".

De acordo com Musse (2008, p. 41), tais pessoas constituem-se como sujeitos de direito na medida em que "Ihes é reconhecida, social, ética e juridicamente, a autonomia 
ético-jurídica" e em que "exercem seus direitos, sua cidadania e na proporção em que participam da própria construção dessa cidadania". Exemplo disso é a participação desse segmento nas Conferências Nacionais de Saúde Mental, na composição de comissões e associações de usuárias e familiares e na construção e implantação das diretrizes da Lei no $10.216 / 2001$ e das tomadas de decisões para os rumos das novas políticas públicas nessa área, possibilitando o fortalecimento da sua identidade e autonomia individual e de grupo ${ }^{5}$.

Nabuco (2008, p. 14) argumenta que é relevante "traçar o percurso das modificações políticas que levaram os usuários de simples pacientes passivos, os doentes mentais, a usuários ativos que vêm aumentando cada vez mais a sua participação política e se afirmando em uma nova subjetividade.". A emergência das loucas e loucos como sujeitos políticos impõe novos rumos ao debate e outro olhar sobre o universo da loucura. A participação enquanto sujeito político potencializa a sua emancipação na medida em que a sua inserção efetiva no movimento gera a construção de uma organização coletiva, seja nas associações ou nos núcleos ligados ao movimento.

Nesse caso, cabe resgatar a singularidade como dimensão significativa para o protagonismo das loucas e loucos como sujeitos políticos. Tendo em vista que as diferenças que o sofrimento mental impõe não justificam a exclusão das loucas e loucos, destaca-se o direito à singularidade como um direito do sujeito a ser tratado com igual consideração e respeito em suas peculiaridades, ou seja, que exige a garantia da igualdade na diferença (SILVA, 2007). Trata-se do reconhecimento da diferença como garantia do direito à igualdade, ou seja, como defende Silva $(2007$, p. 106), o que se exige em relação à pessoa em sofrimento mental é o "direito constitucional à igualdade na sua diferença". Assim, o respeito à singularidade dessas pessoas se expressa na "eliminação de todas as formas estigmatizantes, violentas e excludentes de se tratar a loucura em qualquer âmbito - social, econômico, jurídico, cultural - em que ela se manifeste" (SILVA, 2007, p. 123).

Para Birman (1992, p. 72), a cidadania das loucas e loucos é uma das questões centrais trazidas pela Reforma Psiquiátrica,

começando a circular de maneira decisiva entre nós nos anos oitenta sob a forma de que o Estado brasileiro teria uma "dívida" real para com os doentes

\footnotetext{
5 Tal participação é analisada por Soalheiro (2003, p. 47), destacando-a nos "fóruns oficiais de produção das políticas públicas até os fóruns de discussão e definição de estratégias de um movimento social que impulsiona a Reforma Psiquiátrica Brasileira", trazendo, assim, "a singularidade da perspectiva dos usuários".
} 
mentais, em função de sua longa exclusão social e a consequente ruptura de seus liames sociais. Dessa maneira, se reconhece positivamente o estatuto de cidadania do enfermo mental psiquiatrizado, como a de qualquer outro personagem social. Nesta perspectiva, a "dívida" social com a figura do doente mental se definiria pelo desrespeito para com a sua condição legítima de cidadania. Enfim, o enfermo mental seria positivamente um cidadão que não foi reconhecido devidamente pelo Estado brasileiro, constituindo-se então a privação e a sua consequente condição negativa de cidadania, que caberia ser politicamente resgatada pelos movimentos sociais do campo da saúde mental.

Por isso, a importância da atuação das próprias loucas e loucos na luta pelas mudanças necessárias à construção não apenas de um novo modelo de atenção e cuidado, mas, sobretudo, de novas relações da sociedade com a loucura, constatando a louca como agente transformadora da realidade. Para Amarante (1998), configura-se um novo momento na saúde mental brasileira, com a participação das loucas nas mobilizações pelas transformações nesse campo, uma vez que as loucas e loucos deixam de ser simples objetos da intervenção psiquiátrica, para tornarem-se agentes de transformação da realidade. "Seja nos espaços destas associações, seja em trabalhos culturais, atua-se no surgimento de novas formas de expressão política, ideológica, social, de lazer e participação, que passam a edificar um sentido de cidadania que jamais Ihes foi permitido." (AMARANTE, 1998, p. 121).

Com a inserção das loucas no MA, observa-se, sobretudo, a participação de sujeitos não institucionalizados, ou seja, de loucas e loucos egressos de internações psiquiátricas e que já estão integrados à comunidade, sendo atendidos em serviços territoriais, e que passam a se organizar em associações de usuárias e familiares (VASCONCELOS, 2000, 2016; NABUCO, 2008). A grande diferença trazida pela participação ativa das loucas e loucos desde o início dos anos 90 (que vai se consolidando com a sua organização em associações e coletivos) é a nova identidade impressa no MA, pois são incorporadas as vivências dos sujeitos que experienciam a loucura, o que vai repercutir nos modos de luta por direitos. Nesse sentido, o MA se consolida como um novo sujeito social, a partir das suas práticas sociais e dos novos direitos que elas anunciam.

O reconhecimento das loucas e loucos como sujeitos ativos e competentes impulsiona a sua inserção nos espaços sociais dos quais antes eram privados. Esse aspecto da participação efetiva das loucas e loucos no MA se concretizou, sobretudo, na criação de associações de usuárias e familiares no país, desde o final dos anos 70, e de 
forma mais expressiva nos anos 90. Tais dispositivos associativos incorporaram a dimensão do empoderamento de usuárias dos serviços, na perspectiva de enfrentamento dos desafios inerentes a essa temática para o campo da atenção em saúde mental e das políticas públicas em geral (VASCONCELOS, 2003, 2016). Como recorda Fazenda (2008, p. 43), o movimento de empoderamento "é consequência de uma evolução nas concepções de autonomia e responsabilidade dos indivíduos, e de uma maior consciência dos mecanismos de discriminação e exclusão que se geram na sociedade.".

Partindo da recuperação histórica das mobilizações pela aprovação da política pública de saúde mental para o país, Pedro Delgado (2011) salienta a participação das usuárias dos serviços de saúde mental como delegadas na II Conferência Nacional de Saúde Mental (1992), após participarem das conferências municipais pelo Brasil, e revela que não saíram mais da cena política como protagonistas ${ }^{6}$. Este autor destaca também que na III Conferência Nacional de Saúde Mental, realizada em 2001, as usuárias foram mais numerosas, mais organizadas e mais implicadas na grande responsabilidade de que estavam investidas, como cidadãs que "estavam 'criando', no sentido de Castoriadis, em diálogo com os profissionais e o Estado, as bases consensuais para a construção e consolidação da política pública de saúde mental." (DELGADO, 2011, p. 116).

"Reconhecer as diferentes identidades pode, ao invés de implicar em fragmentações, fazer valer o princípio da pluralidade e da construção de espaços públicos que respeitem as diferentes falas e lugares dos diferentes sujeitos." (LUCHMANN; RODRIGUES, 2007, p. 405). Para tanto, ações direcionadas ao empoderamento dos sujeitos, com destaque para as loucas e loucos, e o respeito às suas especificidades deverão ser adotadas. Trata-se, portanto, não apenas do aumento do peso político das reivindicações do MA, mas da urgência na redefinição dos direitos das loucas e loucos a partir da sua efetiva participação e das suas próprias experiências, uma vez que a luta foi ampliada para a arena de decisão em torno das leis e das políticas

\footnotetext{
${ }^{6}$ A participação ativa das usuárias nessa II Conferência foi uma novidade, tendo em vista que houve "delegados divididos de forma paritária entre usuários e sociedade civil, governo e prestadores de serviços." (SOALHEIRO, 2003, p. 21). De acordo com Soalheiro (2003), em 1991, em São Paulo, foi realizado o primeiro Encontro Nacional de Entidades de Usuários e Familiares, com caráter preparatório para a referida II Conferência, o que acarretou a participação expressiva das usuárias nessa Conferência. Além disso, tal inserção contribuiu para a organização dos Encontros de Usuários e Familiares que viriam a ser realizados nos anos seguintes.
} 
públicas de saúde mental e de outras políticas sociais garantidoras dos direitos dessas pessoas.

De acordo com Rosemary Pereira (2004, p. 13),

Diversamente de outras áreas em que as discussões eram protagonizadas exclusivamente pelo corpo técnico especializado, a saúde mental teve como atores privilegiados, não só os profissionais da área, mas também outros setores da sociedade. A participação ativa dos usuários, familiares e do movimento social em torno da luta por uma sociedade sem manicômios tornou-se cada vez mais preponderante e singular na história brasileira.

Nessa perspectiva, Emerich, Campos e Passos (2014, p. 694) trazem outro aspecto para a reflexão sobre a emergência dos sujeitos de direitos, afirmando que esta somente pode ocorrer no plano coletivo, "por um lado, como prática vivida de intersubjetividade (pactuação, produção de regras) e, por outro, a partir da gestão coletiva e compartilhada do cuidado, que geste modos de existência mais livres, com incorporação efetiva da autonomia dos usuários e dos direitos humanos.". Esta questão tem estado cada vez mais presente nos modos de organização das loucas e loucos na sua luta por direitos, reverberando, inclusive, na estrutura das associações de usuárias e familiares das quais fazem parte.

Para Sousa Junior (2008, p. 146-147), os novos movimentos sociais, caracterizados pelas suas ações sociais, observados como indicadores da emergência de "novas identidades coletivas (coletividades políticas, sujeitos coletivos), puderam elaborar um quadro de significações culturais de suas próprias experiências, ou seja, do modo como vivenciam suas relações, identificam interesses, elaboram suas identidades e afirmam direitos.".

Assim, conforme Sousa Junior (2008), o sujeito coletivo de direito somente possui a titulação do direito através da coletividade, mas isso não se confunde com o mero agrupamento de direitos individuais, sejam eles difusos ou homogêneos. Tal categoria pressupõe, necessariamente, a atuação dos movimentos sociais que conciliam a bagagem histórica e o conhecimento empírico de suas reivindicações ao contexto político e social em que se encontram. Adota-se, portanto, o conceito de movimentos sociais como protagonistas de processos de transformação social (GOHN, 2014) e como "manifestações de um comportamento de contestação da ordem social vigente" (SADER, 1995). Tratam-se de movimentos engajados com um projeto de emancipação social que tenha a capacidade de transformar as relações injustas e desiguais existentes no mundo, além da "emergência de novos padrões de práticas coletivas" e igualmente da mudança 
em relação às representações elaboradas sobre essas práticas e sobre as classes trabalhadoras (SADER, 1995, p. 34).

Esta perspectiva nasce da análise da atuação dos movimentos sociais, indicando a sua capacidade de instaurar novas práticas políticas, possibilitando a abertura de espaços sociais inéditos, através da auto-organização e autodeterminação desses novos atores, muitas vezes, à margem ou em contraposição aos espaços já existentes para a sua expressão tradicional. Segundo Sousa Junior (2002, p. 63),

A análise da experiência da ação coletiva dos novos sujeitos sociais, que se exprime no exercício da cidadania ativa, designa uma prática social que autoriza estabelecer, em perspectiva jurídica, estas novas configurações, tais como a determinação de espaços sociais a partir dos quais se enunciam direitos novos, a constituição de novos processos sociais e de novos direitos e a afirmação teórica do sujeito coletivo de direito.

Tendo em vista que sujeitos coletivos de direitos são sujeitos emergentes que realizam sua subjetividade jurídica no coletivo, capazes de: a) elaborar um projeto político de transformação social e b) elaborar a sua representação como sujeito coletivo de direito (SOUSA JUNIOR, 2008), de acordo com as características e aspectos acima abordados, o Movimento Antimanicomial pode ser considerado um sujeito coletivo de direito. Como analisa Sousa Junior (2002, p. 89), "A questão que se coloca, a partir da experiência da ação coletiva dos novos sujeitos sociais, é a da designação jurídica destas práticas sociais, em configuração determinada pelos processos sociais, e os direitos novos que elas enunciam.".

Observando o seu percurso, identifica-se a capacidade do MA de elaborar um projeto político de transformação social, e, além disso, de levar suas experiências de representação na perspectiva de enunciarem direitos, como se verifica no complexo processo da Reforma Psiquiátrica brasileira, que é fruto da atuação do MA e trouxe à tona uma série de direitos pensados, formulados e reivindicados pelos segmentos que 0 compõem ao longo da sua luta (AMARANTE, 1997, 2017; VASCONCELOS, 2000; DELGADO, 2011), como se verá mais adiante com a caracterização da sua mobilização jurídico-política.

Tal constatação é corroborada por Pedro Delgado (1992, p. 213) ao abordar a cidadania a partir da ótica das políticas sociais, que "enuncia seu problema através da reivindicação da equidade (no estado de bem-estar social, no socialismo ou, de maneira diversa, na utopia liberal). A cidadania desses diferentes que se tornam desiguais, terá que buscar sua própria forma de enunciação.". E é justamente a perspectiva de enunciar 
direitos a partir das mobilizações da luta antimanicomial, incluindo esses sujeitos diferentes, que constitui uma das marcas mais significativas do MA. Nesse sentido, é a participação das usuárias e suas familiares no movimento que vem sedimentar a urgência da redefinição dos direitos das loucas e loucos.

Essa participação passou a ser observada com o progressivo "crescimento de um movimento reivindicatório específico, com uma agenda política própria", seja pela redação de uma primeira carta de direitos, na década de 90 , seja pela realização de encontros nacionais e uma crescente participação no cenário da Reforma Psiquiátrica (SOALHEIRO, 2003, p. 107). Destaca-se, também, a participação desses sujeitos políticos nos conselhos de políticas públicas, sobretudo a partir da sua organização em associações de usuários e familiares, passando a disputar a representação nesses espaços (VASCONCELOS, 2016).

Segundo Rosemary Pereira (2004, p. 179), o Projeto de Lei n. 3657/89 (que originou a Lei da Reforma Psiquiátrica) apresentado à Câmara dos Deputados teve a fundamental participação do Movimento Nacional de Luta Antimanicomial que, em sua trajetória, "delimitou o problema a ser enfrentado e propôs uma forma de resolução. Reforçou a importância do enfrentamento das instituições de exclusão social e a elaboração de estratégias para garantir os direitos sociais e a própria cidadania dos loucos.".

Como discutido na obra "O Direito Achado na Rua: concepção e prática" (SOUSA JUNIOR, 2015, p. 133):

\begin{abstract}
Identificar os sujeitos participantes e atuantes enquanto sujeitos coletivos, capazes de levar suas vivências/experiências de representação na perspectiva de enunciarem direitos, é uma tarefa árdua. Não pela sua ausência, mas muitas vezes pela invisibilidade que lhe é imposta. Essa posição de "invisibilidade" se justifica pela dificuldade de reconhecimento do pluralismo social para justificar uma esfera pública controlável e homogênea, com as formas de opressão, exclusão e discriminação escondidas (Santos, 2007a).
\end{abstract}

De acordo com Santos (2005, p. 21), o que se observa é o desperdício das experiências, tendo em vista a ocultação e o descrédito dessas práticas, "quer da experiência social que já se encontra disponível, quer da experiência que não estando ainda disponível, é contudo realisticamente possível". Daí a importância da "sociologia das ausências", que, nos termos de Santos (2004), trata-se de uma investigação que visa demonstrar que o que não existe é, na verdade, ativamente produzido como não existente e tem como objetivo transformar objetos impossíveis em possíveis, e, com 
base neles, transformar as ausências em presenças. Portanto, o não desperdício das experiências deve ser condição primeira para construir novas formas de enunciação dos direitos. O MA demonstra como transformou o seu acúmulo em instrumentos e mecanismos de garantia de direitos às loucas e loucos no Brasil, como se observa na sua atuação política e jurídica (CORREIA, 2018).

A título de exemplo foi o que aconteceu em Santos - SP, no ano de 1989, com a intervenção municipal na Casa de Saúde Anchieta, hospital psiquiátrico privado denunciado pelas diversas violações de direitos humanos cometidas contra as pessoas ali internadas. Tal intervenção foi realizada num contexto de redemocratização e reforma das instituições do país, além dos desejos de mudança e transformação que bebiam da experiência da reforma sanitária implementada na Itália. Como recorda Kinoshita (2009, p. 1), o "executivo municipal arrogou a si a responsabilidade constitucional de garantir tanto o tratamento quanto os direitos individuais, e levou adiante a tese vitoriosa de que apenas através da Intervenção seria possível alcançar tal objetivo.". Com a recém promulgada Constituição Federal de 1988, esta tornou-se instrumento para garantir os direitos fundamentais das pessoas internadas naquela instituição em contraposição ao poder da propriedade privada, constituindo a principal fundamentação para a intervenção realizada.

A partir dali, buscou-se a transformação prática da realidade institucional, de acordo com os ensinamentos da experiência italiana na saúde mental. Tratava-se de transformar não apenas a concepção de assistência às pessoas loucas, mas ampliar o debate, colocando em jogo "as relações sociais e políticas como um todo" e desconstruindo a "lógica que mantém o manicômio como necessário." (KINOSHITA, 2009, p. 2). Tal processo desembocou na inauguração do primeiro Núcleo de Apoio Psicossocial (NAPS) ${ }^{7}$ do país, que teve a participação de militantes do MA no seu projeto (NICÁCIO, 1994; KINOSHITA, 1997; YASUI, 2010). Acerca dessa experiência, Nicácio (1994, p. 24) afirma que a transformação empreendida em Santos projetou "a construção da Saúde Mental como território de cidadania, emancipação e reprodução social.". Integrantes do MA tiveram papel central na construção desse inédito serviço de

\footnotetext{
7 O Núcleo de Atenção Psicossocial (NAPS) é um serviço extra-hospitalar, substitutivo ao modelo manicomial, que presta assistência multiprofissional 24 horas por dia, todos os dias da semana, tendo como centralidade a necessidade das pessoas loucas, buscando, ainda, a sua reinserção social (NICÁCIO, 1994). O Centro de Atenção Psicossocial (CAPS) apresenta similaridade ao NAPS, caracterizando-se pela acessibilidade local e pela interdisciplinaridade. Após a vigência da Lei no 10.216 em 2001, o CAPS se consolidou como política pública pelo Ministério da Saúde, que publicou a Portaria no 336, de 19 de fevereiro de 2002, a qual prevê as modalidades de CAPS e as atividades que devem ser ali prestadas.
} 
saúde mental junto ao poder público municipal, que foi inspirado na experiência da Psiquiatria Democrática italiana.

A categoria "sujeito coletivo de direito" é crucial nesta reflexão, uma vez que na jornada reivindicatória por transformações no âmbito da saúde mental liderada pelo MA, destaca-se a sua grande influência não só na elaboração da Lei da Reforma Psiquiátrica (como é chamada a Lei no 10.216/2001), mas também na formulação das políticas públicas de saúde mental a partir das experiências que ajudou a construir em algumas cidades do país na segunda metade da década de 80 . Além do que foi realizado em Santos, como mencionado acima, em São Paulo, dois anos antes, era inaugurado o Centro de Atenção Psicossocial Professor Luiz da Rocha Cerqueira (CAPS Itapeva). Esta experiência representou uma ruptura com as práticas cristalizadas e pouco resolutivas dominantes à época e instigou a criação de novos serviços e a transformação daqueles que já existiam.

Destaca-se, ainda, a publicação da Portaria no 189, de 19 de novembro de 1991, e da Portaria no 224, de 29 de janeiro de 1992, ambas do Ministério da Saúde, que estabeleceram e regulamentaram novos procedimentos e dispositivos na área da assistência psiquiátrica e atenção psicossocial (como os Núcleos e Centros de Atenção Psicossocial), com clara inspiração nas referidas práticas pioneiras e inovadoras realizadas naqueles municípios, com a participação ativa de integrantes do MA. Tais portarias tiveram efeito indutor, redirecionando os recursos financeiros para as modalidades de assistência alternativas à internação em hospital psiquiátrico (ALVES et al., 1994).

Nesse percurso, observa-se a perspectiva teórico-prática de O Direito Achado na Rua, que traz questões-chave para esse debate nas palavras de Sousa Junior (2008, p. 288):

O humanismo de O Direito Achado na Rua, como salienta o Professor Roberto Lyra Filho $(1982,1983,1986)$, formulador de seus princípios, longe de se constituir numa idolatria do homem por si mesmo, procura restituir a confiança de seu poder em quebrar as algemas que o aprisionam nas opressões e espoliações que o alienam na História, para se fazer sujeito ativo, capaz de transformar o seu destino e conduzir a sua própria experiência na direção de novos espaços libertadores. Mas a liberdade, ele acrescenta, "não é um dom, nem uma subordinação a um destino. Ela é tarefa, que se realiza na História, porque não nos libertamos isoladamente, mas em conjunto." E se ela não existe em si, o Direito é comumente a sua expressão, porque ele é a sua afirmação histórico-social "que acompanha a conscientização de liberdades antes não pensadas (...) e de contradições entre as liberdades estabelecidas (...)". 
Tomando como referência tais elementos do pensamento de Roberto Lyra Filho e de José Geraldo de Sousa Junior, que embasam O Direito Achado na Rua, configurando o direito como legítima organização social da liberdade, indaga-se qual o seu reflexo no campo das lutas pelo reconhecimento e garantia dos direitos das loucas e loucos no Brasil. A partir da atuação dos segmentos do MA, identifica-se que o direito que dele emerge não se constitui como ordem estagnada, mas como "positivação, em luta, dos princípios libertadores, na totalidade social em movimento" (LYRA FILHO, 1982, p. 13). Na perspectiva histórico-dialética do direito, debatida por Lyra Filho (1982) e constitutiva de O Direito Achado na Rua, resta clara a afirmação histórica no processo de conquista dos direitos no âmbito da luta antimanicomial, que não se coaduna com a concepção liberal, pela qual o direito reconhecido e expresso em normas jurídicas seria suficiente para garantir sua efetividade.

Como aduz Vasconcelos (2014, p. 276-277),

Uma visão histórico-crítica dos direitos humanos e das políticas sociais implica em reconhecer que o grau de implementação e garantia destes direitos é determinado pela conjunção de fatores e interesses econômicos, políticos e ideológicos, refletindo a correlação de forças na sociedade. Além disso, os usuários e cidadãos comuns sabem disso intuitivamente, têm uma noção muito clara dos limites da assistência, mas também têm uma enorme expectativa de que o contrário seja verdade, para que seus problemas e impasses sejam efetivamente encaminhados. A visão liberal tenta manter a ilusão de que os direitos estão garantidos, ou mobiliza um impulso voluntarista de ação, como se bastasse apenas "correr atrás" deles com afinco, para que eles sejam efetivados, perspectiva que não se sustenta na prática, pelo menos desta forma individualizada e imediatista. Dada a situação atual de precariedade e sucateamento da assistência, de avanço dos interesses privatistas e lucrativos no campo da saúde e saúde mental, na presente conjuntura neoliberal, a tendência hegemônica é desses direitos serem negligenciados, e aí, a frustração que se segue leva à desmobilização, à descrença, ao isolamento e à passividade.

Com a aprovação da Lei da Reforma Psiquiátrica em 2001, o ordenamento jurídico brasileiro começou a avançar na garantia dos direitos das loucas e loucos, com novos instrumentos para a promoção desses direitos ${ }^{8}$. Porém, a vigência dessa legislação

\footnotetext{
${ }^{8}$ A criação dos Serviços Residenciais Terapêuticos (casas residenciais localizadas no espaço urbano para atender as necessidades de moradia das loucas e loucos, institucionalizadas ou não, através da Portaria no 106/2000; o auxílio reabilitação para pessoas egressas de internações psiquiátricas (Programa De Volta Para Casa), instituído pela Lei no 10.708/2003; diretrizes de redução de leitos previstas em diversas Portarias do Ministério da Saúde, que estabelecem a redução progressiva de leitos psiquiátricos; além das mudanças no Código Civil sobre a capacidade das pessoas com deficiência (aqui incluídas as pessoas com diagnóstico de transtorno mental), com destaque para a Lei Brasileira de Inclusão, Lei № 13.146/2015, que define que a deficiência não afeta a plena capacidade civil da pessoa.
} 
não imobilizou o MA e demais grupos que atuam no âmbito da luta antimanicomial, embora, se constate que, nos anos que se seguiram à aprovação da referida lei, as mobilizações tenham diminuído e muitas das ações tenham se deslocado da sociedade civil para o interior Estado, como alerta Yasui (2010, p. 60): "Tem-se a impressão de que os principais atores estão nos gabinetes ministeriais, produzindo normas e portarias e não estão mais nas forças vivas da sociedade, nas instituições e nos serviços, como ativos protagonistas políticos.". Nesse sentido, uma vez que tais atores passam a integrar as equipes gestoras de programas de saúde mental, identifica-se pouco investimento na disseminação de organizações de base e associações de usuários e trabalhadores, significando "um relativo descompromisso com a perspectiva de buscar construir gradualmente um deslocamento mais efetivo do poder para o público alvo dos programas de saúde mental." (VASCONCELOS, 2016, p. 99). Isso fragiliza o MA, uma vez que uma das estratégias mais potentes para a luta por direitos desenvolvida nesse campo é a organização associativa e sua representação em espaços de construção de políticas públicas, como os conselhos municipais e estaduais de saúde.

De qualquer forma, o que se observou nos últimos anos no âmbito das ações do MA foi a tentativa de que tal lei não se tornasse "letra morta", ou seja, de que o seu texto não deixasse de ser efetivamente implementado. Isso ocorreu, por exemplo, nas ações de diversas associações de usuárias e familiares que passaram a exercer o controle social das políticas públicas de saúde mental implantadas nos estados e municípios, seja a partir da sua atuação nos conselhos municipais e estaduais de saúde, seja em audiências públicas, reuniões de orçamento participativo, mobilizações pelo passe livre na saúde mental, pesquisas avaliativas dos serviços substitutivos que constituem a Rede de Atenção Psicossocial (RAPS) ou nas Conferências de Saúde Mental (VASCONCELOS, 2016).

É importante reconhecer os processos institucionais pelos quais os direitos adquirem sentido concreto na vida dessas pessoas e como as práticas sociais que criam direitos e formas de gestão dos conflitos sociais não ocorrem necessariamente no espaço do direito estatal e seus marcos institucionais (SANTOS, 2014). Ao lado disso, merece destaque outra questão, levantada por Emerich, Onocko e Passos (2014, p. 690), ao afirmarem que a experiência de direito construída na práxis e garantida pela lei "permite o reposicionamento subjetivo tanto dos trabalhadores - aí incluídos os gestores - quanto dos usuários, ampliando o trabalho de profissional de referência e sua 
participação nos espaços coletivos, assim como a vivência efetiva dos direitos pelos usuários.". Porém, cabe registrar que a construção dos direitos por esse grupo social também se deu no espaço estatal, a exemplo das disputas junto ao Congresso Nacional e ao Poder Executivo, seja no governo federal ou nos governos estaduais e municipais (PEREIRA, 2004; VASCONCELOS, 2016; CORREIA, 2018), entendendo que estes também são espaços de construção e reafirmação de direitos.

Identificam-se, portanto, outros elementos diretamente relacionados à perspectiva de $O$ Direito Achado na Rua, quais sejam: a) a determinação do espaço político no qual são desenvolvidas as práticas sociais que enunciam direitos; e b) a capacidade de elaboração da sua representação como sujeito coletivo de direito. Observa-se que o processo de luta por direitos na saúde mental ocorre nos espaços coletivos, agregando trabalhadoras, loucas e loucos, que configuram a sua representação a partir das suas diferenças, significações, experiências e participações em tais espaços. Daí a importância de vivenciar a alteridade no coletivo. A igualdade e a liberdade desses atores devem ser consideradas como pré-requisitos para legitimar o sujeito coletivo, além de exercitar a capacidade de ser ouvidos e que a ouvinte possa acessar as chaves da compreensão dos conteúdos expostos (SOUSA JUNIOR, 2015).

Em reflexão e produção coletivas de integrantes do Grupo de Pesquisa O Direito Achado na Rua (SOUSA JUNIOR, 2015, p. 137), enfatiza-se:

O diálogo social pode ser ferramenta que se atrela a isso para dar legitimidade ao sujeito coletivo. Internamente, esse exercício de mediar sem transformar em dominação, em colonização do outro, talvez um desarmar de egos e o despertar da sensibilidade amorosa permita um viver na alteridade a que propõe Warat (2004). Na esfera pública: o processo de ruptura para viver e reconhecer a diversidade, a pluralidade dos sujeitos é uma aventura que começa internamente no ser e transborda para o coletivo, uma alteridade ética, que se constrói na prática e não em abstrações teóricas, o que justifica a forte defesa da categoria: sujeito coletivo de direito.

A partir desse entendimento, compreende-se que "é possível uma ação coletiva, somando as preocupações do exercício das liberdades civis e políticas com a proteção e eficácia dos direitos sociais, para permitir que seja atendida a condição de igualdade da pessoa ou do grupo." (SOUSA JUNIOR, 2015, p. 137). E a natureza jurídica da mencionada categoria é definida por Sousa Junior (2008, p. 145) como: "sujeito coletivo capaz de elaborar um projeto político de transformação social e elaborar a sua representação teórica como sujeito coletivo de direito". 


\section{Considerações finais: a luta continua!}

O projeto político construído pelo Movimento Antimanicomial vem se concretizando com a Reforma Psiquiátrica brasileira, que tem operado promissoras mudanças no campo do cuidado em saúde mental (BRASIL, 2015). Ao desenvolver novas práticas que se propõem a efetivar a desinstitucionalização, promovendo o fortalecimento dos serviços substitutivos inseridos no contexto descentralizado do Sistema Único de Saúde (SUS), a Reforma Psiquiátrica materializa as reivindicações formuladas pela mobilização jurídicopolítica empreendida pelo referido movimento.

A atuação do MA em torno da luta pelos direitos das loucas e loucos pode ser caracterizada como uma mobilização política e jurídica. Aqui destaca-se a importância da junção das lutas políticas e jurídicas como mecanismo necessário às conquistas do movimento e suas assessorias no campo jurídico (SANTOS, 2011), visando alcançar a visibilidade social e a atenção dos órgãos públicos para o conflito. Identifica-se a percepção do direito como processo na mobilização jurídico-política empreendida pelo MA, que aponta a conquista da legislação que prevê direitos às loucas e loucos como um instrumento e não como um fim da luta no campo da saúde mental, e, portanto, deve impulsionar novas estratégias de mobilização do direito, reforçando o poder desse grupo subalternizado.

Ressalte-se a mobilização nacional do MA ocorrida nos dias 08 e 09 de dezembro de 2017, o "Encontro de Bauru: 30 anos por uma sociedade sem manicômios", em Bauru-SP, que reuniu cerca de duas mil pessoas de quase todos os estados do Brasil, sendo reconhecido como um momento de fortalecimento da luta antimanicomial. Os debates ali travados trouxeram as dimensões e desafios da luta antimanicomial nas diferentes regiões do país, pautaram novos temas para a área da saúde mental, e, ainda, novas formas de enfrentamento e mobilização no contexto de sucateamento dos serviços de saúde mental e de retrocessos no âmbito do Sistema Único de Saúde (CORREIA, 2018).

Os vários segmentos do MA presentes no Encontro de Bauru se debruçaram sobre as propostas do Ministério da Saúde que apresentavam ameaças à consolidação e ao fortalecimento da Rede de Atenção Psicossocial ${ }^{9}$, se manifestando de forma contrária

9 Tais propostas foram o reinvestimento em leitos de hospitais psiquiátricos; o encaminhamento de adolescentes em uso de álcool e outras drogas para o Centro de Atenção Psicossocial Álcool e Drogas (serviço voltado às pessoas adultas); a inclusão do ambulatório de saúde mental na Rede de Atenção 
às mesmas. Mesmo sob a vigência da Lei da Reforma Psiquiátrica, foi editada a Portaria no 3.588/2017 do Ministério da Saúde (BRASIL, 2017), a qual contraria os princípios dessa lei. Tanto, que a Procuradoria Federal dos Direitos do Cidadão passou a estudar alguma medida, juntamente com organizações e segmentos do MA, para questionar as mudanças impostas por essa nova normativa ${ }^{10}$, como já havia sinalizado nessa Nota Pública, de 12 de dezembro de 2017: “o Ministério Público Federal atuará por meio de todas as medidas judiciais cabíveis para assegurar a desinstitucionalização dos pacientes de hospitais psiquiátricos e para que não se perpetue a exclusão e a violação dos direitos dessa população."

Na plenária final do referido Encontro, foram lidas as propostas construídas para os eixos de luta e estratégias de resistência, que emergiram das Rodas de Conversa temáticas realizadas naqueles dois dias, e a Carta de Bauru $-30 \operatorname{anos}^{11}$.

Vale frisar que esta mobilização foi ainda mais forte tendo em vista a conjuntura política atual do Brasil com o golpe de 2016, que impôs "uma ruptura com a base de legitimidade do sistema constitucional-jurídico, um atentado à democracia, uma forma de traduzir, sem nenhuma sutileza, o Estado Democrático da Direita, que se vale da lei para esvaziá-la de suas melhores promessas." (SOUSA JUNIOR, 2017, p. 244).

Após o golpe, com o governo ilegítimo de Michel Temer ${ }^{12}$, muitos retrocessos têm ocorrido nas mais diversas áreas, especialmente no campo dos direitos sociais, com destaque para os direitos à saúde, à educação, à assistência social, ao trabalho e à previdência social (STEFANO; MENDONÇA, 2018). Portanto, impõe-se reorientar os sentidos das mobilizações para a retomada do projeto de sociedade a partir das expectativas solidárias e emancipatórias vivenciadas legitimamente no social.

A partir desses registros e de acordo com as ideias de Roberto Lyra Filho (1982), a metáfora da rua como espaço público se concretiza na atuação do MA, que consegue

Psicossocial; além do financiamento público das comunidades terapêuticas, conforme consta no relatório final do Encontro de Bauru. Disponível em: <https://site.cfp.org.br/wp-content/uploads/2018/11/relatorioencontro-de-bauru-1.pdf>. Acesso em: 10 ago. 2019.

10 Disponível em: <http://www.abrasme.org.br/informativo/view?ID_INFORMATIVO=371>. Acesso em: 10 out. 2018.

11 Disponível em: <http://site.cfp.org.br/wp-content/uploads/2017/12/CARTA-DE-BAURU-30-ANOS.pdf.>. Acesso em: 20 out. 2018.

12 O caráter golpista que caracterizou o processo de impeachment é explicitado por José Geraldo de Sousa Junior (2017, p. 242-243), ao enfatizar que ele "configurou um golpe institucional armado contra um projeto de sociedade, uma plataforma política e uma concepção de democracia. Por isso, ele se realiza e é conduzido contra a Constituição que representa esses valores e contra os sujeitos que nela se inscrevem, os trabalhadores, os marginalizados, os excluídos, os subalternos emergentes das lutas decoloniais que estão na base da formação social brasileira e das múltiplas lutas por identidade e reconhecimento.". Daí podermos afirmar a ilegitimidade do governo de Michel Temer. 
demonstrar a importância da mobilização política para continuar avançando nas conquistas da Reforma Psiquiátrica brasileira, tendo em vista que estas não se reduzem à aprovação de uma lei. Constata-se que as recentes mudanças na Política Nacional de Saúde Mental ${ }^{13}$ são combustíveis para continuar e fortalecer a luta antimanicomial no país.

\section{Referências bibliográficas}

ALVES, Domingos Sávio Nascimento et al. Reestruturação da atenção em saúde mental: situação atual, diretrizes e estratégias. In: AMARANTE, Paulo. Psiquiatria Social $e$ Reforma Psiquiátrica. Rio de Janeiro: Fiocruz, 1994. p. 197-204.

AMARANTE, Paulo Duarte de Carvalho. Loucura, Cultura e Subjetividade: Conceitos e Estratégias, Percursos e Atores da Reforma Psiquiátrica Brasileira. In: FLEURY, Sonia (Org.). Saúde e democracia: a luta do CEBES. São Paulo: Lemos Editorial, 1997. p. 163185.

. Loucos pela vida: a trajetória da reforma psiquiátrica no Brasil. 2. ed. Rio de Janeiro: Fiocruz, 1998.

Teoria e crítica em saúde mental: textos selecionados. 2. ed. São Paulo: Zagodoni, 2017.

BANDEIRA, Lourdes. A contribuição da crítica feminista à ciência. Estudos Feministas. Florianópolis, 16(1): 288, janeiro-abril/2008. p. 207-228. Disponível em: <http://www.scielo.br/pdf/ref/v16n1/a20v16n1.pdf>. Acesso em: 20 ago. 2019.

BARBOSA, Guilherme Correa; COSTA, Tatiana Garcia da; MORENO, Vânia. Movimento da luta antimanicomial: trajetória, avanços e desafios. Cadernos Brasileiros de Saúde Mental, Rio de Janeiro, v. 4, n. 8, p. 45-50, jan./jun. 2012.

BASAGLIA, Franco. A psiquiatria alternativa: contra o pessimismo da razão, o otimismo

\footnotetext{
13 A Portaria no 3.659, de 14 de novembro de 2018, que suspendeu o repasse do recurso financeiro destinado ao incentivo de custeio mensal de Centros de Atenção Psicossocial (CAPS), Serviços Residenciais Terapêuticos (SRT), Unidades de Acolhimento (UA) e de Leitos de Saúde Mental em Hospital Geral, integrantes da RAPS, por ausência de registros de procedimentos nos sistemas de informação do Sistema Único de Saúde (SUS); a Portaria no 2.434, de 15 de agosto de 2018, que altera a Portaria de Consolidação $\mathrm{n}^{\circ}$ 6/GM/MS, de 28 de setembro de 2017, para reajustar o valor das diárias de internação hospitalar acima de 90 (noventa) dias do Incentivo para Internação nos Hospitais Psiquiátricos, estimulando, assim, as internações; além de outras mudanças sugeridas a partir da Nota Técnica no 11/2019CGMAD/DAPES/SAS/MS, publicada em 04 de fevereiro de 2019 pelo Ministério da Saúde (CORREIA; MARTINS; REQUIÃO, 2019).
} 
da prática. São Paulo: Brasil Debates, 1979.

Conversazione: a proposito della nuova legge 180. In: BASAGLIA, Franca Ongaro (a cura di). Franco Basaglia. Scritti II, 1953-1968. Dall'apertura del manicomio ala nuova legge sull'assistenza psichiatrica. Torino: Einaudi, 1982. p. 473-485.

BASAGLIA, Franco; BASAGLIA, Franca Ongaro. La maggioranza deviante. L'ideologia del controlo sociale totale. Torino: Einaudi, 1971.

BIRMAN, Joel. A cidadania tresloucada - notas introdutórias sobre a cidadania dos doentes mentais. In: BEZERRA JÚNIOR, Benilton; AMARANTE, Paulo. (Orgs.). Psiquiatria sem hospício: contribuições ao estudo da reforma psiquiátrica. Rio de Janeiro: RelumeDumará, 1992. p. 71-90.

BRASIL. Lei n.o 10.216, de 06 de abril de 2001. Dispõe sobre a proteção e os direitos das pessoas portadoras de transtornos mentais e redireciona o modelo assistencial em saúde mental.

BRASIL. Ministério da Saúde. Secretaria de Atenção à Saúde. Departamento de Ações Programáticas Estratégicas. Cadernos HumanizaSUS. Volume 5. Saúde Mental. Brasília: Ministério da Saúde, 2015.

BRASIL. Ministério da Saúde. Portaria no 3.588, de 21 de dezembro de 2017. Altera as Portarias de Consolidação no 3 e no 6, de 28 de setembro de 2017, para dispor sobre a Rede de Atenção Psicossocial, e dá outras providências.

CAMARGO, Tereza da Silva Pereira et al. (Orgs.). CEBES 40 anos: memórias do futuro. Rio de Janeiro: CEBES, 2016.

CORREIA, Ludmila Cerqueira. Por uma pedagogia da loucura: experiências de assessoria jurídica popular universitária no contexto da Reforma Psiquiátrica brasileira. 2018. $383 \mathrm{f}$. Tese (Doutorado em Direito, Estado e Constituição) - Faculdade de Direito, Universidade de Brasília, Brasília, Brasil.

CORREIA, Ludmila Cerqueira; MARTINS, Laércio; REQUIÃO, Maurício. À beira do abismo e ao encontro do absurdo: considerações sociojurídicas sobre a Nota Técnica n. 11/2019 do Ministério da Saúde. Revista Jurídica (FURB). v. 23, no. 50, jan./abr. 2019. p. 1-23. Disponível em: <https://proxy.furb.br/ojs/index.php/juridica/article/view/7918>. Acesso em: 20 ago. 2019.

COSTA, Alexandre Bernardino et al. (Orgs.). O Direito achado na rua: Introdução crítica ao direito à saúde. Brasília: CEAD/UnB, 2008. 
COSTA, Nilson do Rosário; TUNDIS, Silvério Almeida. (Orgs.). Cidadania e loucura: políticas de saúde mental no Brasil. 7. ed. Petrópolis: Vozes, co-edição ABRASCO, 2001.

DELGADO, Pedro Gabriel Godinho. As razões da tutela. Rio de Janeiro: Te Corá, 1992.

Saúde mental e direitos humanos: 10 anos da Lei 10.216/2001. Arquivos Brasileiros de Psicologia. Rio de Janeiro, 63 (2): 114-121, 2011. Disponível em: <http://pepsic.bvsalud.org/pdf/arbp/v63n2/12.pdf>. Acesso em: 20 out. 2018.

EMERICH, Bruno Ferrari; CAMPOS, Rosana Onocko; PASSOS, Eduardo. Direitos na loucura: o que dizem usuários e gestores dos Centros de Atenção Psicossocial. Interface. (Botucatu). 2014; 18(51): 685-96. Disponível em: <http://www.scielo.br/pdf/icse/2014nahead/1807-5762-icse-1807-576220141007.pdf>. Acesso em: 12 nov. 2018.

FAZENDA, Isabel. O puzzle desmanchado: saúde mental, contexto social, reabilitação e cidadania. Lisboa: CLIMEPSI, 2008.

FERNANDES, Maria Inês Assumpção; SCARCELLI, lanni Regia. Psicologia e políticas públicas de saúde: da construção de modelos à implementação de práticas. In: AMARANTE, Paulo (Coord.). Archivos de saúde mental e atenção psicossocial, 2. Rio de Janeiro: Nau, 2005. p. 67-90.

GOHN, Maria da Glória. Novas teorias dos movimentos sociais. 5. ed. São Paulo: Loyola, 2014.

KINOSHITA, Roberto Tykanori. Em busca da cidadania. In: CAMPOS, Florianita Coelho Braga; HENRIQUES, Cláudio Maierovitch Pessanha (Orgs.). Contra a maré à beira-mar: a experiência do SUS em Santos. São Paulo: Hucitec, 1997. p. 67-77.

. Saúde mental e antipsiquiatria em Santos: 20 anos depois. Cadernos Brasileiros de Saúde Mental. Rio de Janeiro, v. 1, n. 1, p. 223-231, jan./abr. 2009. Disponível em: <http://incubadora.periodicos.ufsc.br/index.php/cbsm/article/view/1017/1144>.

Acesso em: 28 nov. 2018.

LUCHMANN, Lígia Helena Hahn; RODRIGUES, Jefferson. O movimento antimanicomial no Brasil. Ciência \& Saúde Coletiva, Rio de Janeiro, v. 12, n. 2, p. 399-407, mar./abr. 2007. Disponível em: <http://www.scielo.br/pdf/csc/v12n2/a16v12n2.pdf>. Acesso em: 28 nov. 2018.

LYRA FILHO, Roberto. O que é direito. São Paulo: Brasiliense, 1982. 
MUSSE, Luciana Barbosa. Novos sujeitos de direitos: as pessoas com transtorno mental na visão da bioética e do biodireito. Rio de Janeiro: Elsevier, 2008.

NABUCO, Edvaldo. Da reclusão à criação: construção da memória dos usuários do Movimento Nacional de Luta Antimanicomial. 2008. 137 f. Dissertação (Mestrado em Memória Social) - Programa de Pós-Graduação em Memória Social, Universidade Federal do Estado do Rio de Janeiro, Rio de Janeiro.

NICÁCIO, Fernanda; AMARANTE, Paulo; BARROS, Denise Dias. Postfazione. I movimenti per la salute mentale in Brasile dagli anni Ottanta. In: BASAGLIA, Franca Ongaro; GIANNICHEDDA, Maria Grazia (a cura di). Conferenze brasiliane. Milano: Raffaello Cortina Editore, 2000. p. 233-257.

NICÁCIO, Maria Fernanda de Silvio. O Processo de Transformação da Saúde Mental em Santos: Desconstrução de Saberes, Instituições e Cultura. 1994. 155 f. Dissertação (Mestrado em Ciências Sociais) - Pontifícia Universidade Católica de São Paulo, São Paulo.

OLIVEIRA, Rayane Noronha; DUQUE, Ana Paula; WEYL, Luana Medeiros. Linguagem inclusiv@: o que é e para que serve?! In: SOUSA JUNIOR, José Geraldo; APOSTOLOVA, Bistra Stefanova; FONSECA, Lívia Gimenes Dias da. O Direito Achado na Rua. Vol. 5. Introdução crítica ao direito das mulheres. p. 129-132.

PEREIRA, Rosemary Corrêa. Políticas de saúde mental no Brasil: o processo de formulação da lei de reforma psiquiátrica (10.216/01). 2004. 244 f. Tese (Doutorado em Ciências na área de Saúde Pública) - Escola Nacional de Saúde Pública Sérgio Arouca, Fundação Oswaldo Cruz, Rio de Janeiro.

ROTELLI, Franco. A instituição inventada. In: NICÁCIO, Fernanda. (Org.). Desinstitucionalização. São Paulo: Hucitec, 2001. p. 89-99.

SADER, Eder. Quando novos personagens entraram em cena. 2. ed. São Paulo: Paz e Terra, 1995.

SANTOS, Boaventura de Sousa. Para uma sociologia das ausências e uma sociologia das emergências. In: SANTOS, Boaventura de Sousa (Org.). Conhecimento Prudente para uma Vida Decente. 'Um discurso sobre as ciências' revisitado. São Paulo: Cortez, 2004. p. 777821.

. O Fórum Social Mundial: Manual de uso. São Paulo: Cortez, 2005.

. Para uma revolução democrática da justiça. 3. ed. São Paulo: Cortez, 2011. 
. O direito dos oprimidos. São Paulo: Cortez, 2014.

SILVA, Janaína Lima Penalva da. O direito fundamental à singularidade do portador de sofrimento mental: uma análise da Lei no 10.216/01 à luz do princípio da Integridade do Direito. 2007. 152 f. Dissertação (Mestrado em Direito, Estado e Constituição) Faculdade de Direito, Universidade de Brasília, Brasília.

SOALHEIRO, Nina. Da experiência subjetiva à prática política: a visão do usuário sobre si, sua condição e seus direitos. 2003. 189 f. Tese (Doutorado em Ciências na área de Saúde Pública) - Escola Nacional de Saúde Pública, Fundação Oswaldo Cruz, Rio de Janeiro.

SOUSA JUNIOR, José Geraldo de (Org.). Sociologia jurídica: condições sociais e possibilidades teóricas. Porto Alegre: Sérgio Fabris, 2002.

Direito como liberdade: o Direito achado na rua: experiências populares emancipatórias de criação do Direito. 2008. 338 f. Tese (Doutorado em Direito, Estado e Constituição) - Faculdade de Direito, Universidade de Brasília, Brasília.

. (Org.). O direito achado na rua: concepção e prática. Rio de Janeiro: Lumen Juris, 2015.

. Resistência ao golpe de 2016: contra a Reforma da Previdência. In: RAMOS, Gustavo Teixeira et al. (Coords.). O golpe de 2016 e a reforma da previdência: narrativas de resistência. Bauru: Canal 6, 2017. p. 242-246.

STEFANO, Daniela; MENDONÇA, Maria Luisa. Direitos humanos no Brasil 2018: relatório da Rede Social de Justiça e Direitos Humanos. São Paulo: Outras expressões, 2018.

VASCONCELOS, Eduardo Mourão. Reinvenção da cidadania, Empowerment no campo da saúde mental e estratégia política no movimento de usuários. In: AMARANTE, Paulo. (Org.). Ensaios: subjetividade, saúde mental, sociedade. Rio de Janeiro: Fiocruz, 2000. p. 169-194.

. O poder que brota da dor e da opressão: empowerment, sua história, teorias e estratégias. São Paulo: Paulus, 2003.

Desafios políticos no campo da saúde mental na atual conjuntura: uma contribuição ao debate da IV Conferência Nacional. In: VASCONCELOS, Eduardo Mourão. (Org.). Desafios políticos da reforma psiquiátrica brasileira. São Paulo: Hucitec, 2010. p. 17-73.

- Impasses políticos atuais do Movimento Nacional de Luta Antimanicomial (MNLA) e propostas de enfrentamento: se não nos transformarmos, o risco é a 
fragmentação e a dispersão política! Cadernos Brasileiros de Saúde Mental, Rio de Janeiro, v. 4, n. 8, p. 57-67, jan./jun. 2012.

- (Coord.). Manual de direitos e deveres dos usuários e familiares em saúde mental e drogas. Rio de Janeiro: Escola do Serviço social da UFRJ; Brasília: Ministério da Saúde, Fundo Nacional de Saúde, 2014.

. Dispositivos associativos e de luta no campo da saúde mental no Brasil: quadro atual, tipologia, desafios e propostas. In: VASCONCELOS, Eduardo Mourão (Org.). Abordagens psicossociais, volume II: reforma psiquiátrica e saúde mental na ótica da cultura e das lutas populares. 2. ed. São Paulo: Hucitec, 2016. p. 56-141.

YASUI, Silvio. Rupturas e encontros: desafios da Reforma Psiquiátrica brasileira. Rio de Janeiro: Fiocruz, 2010.

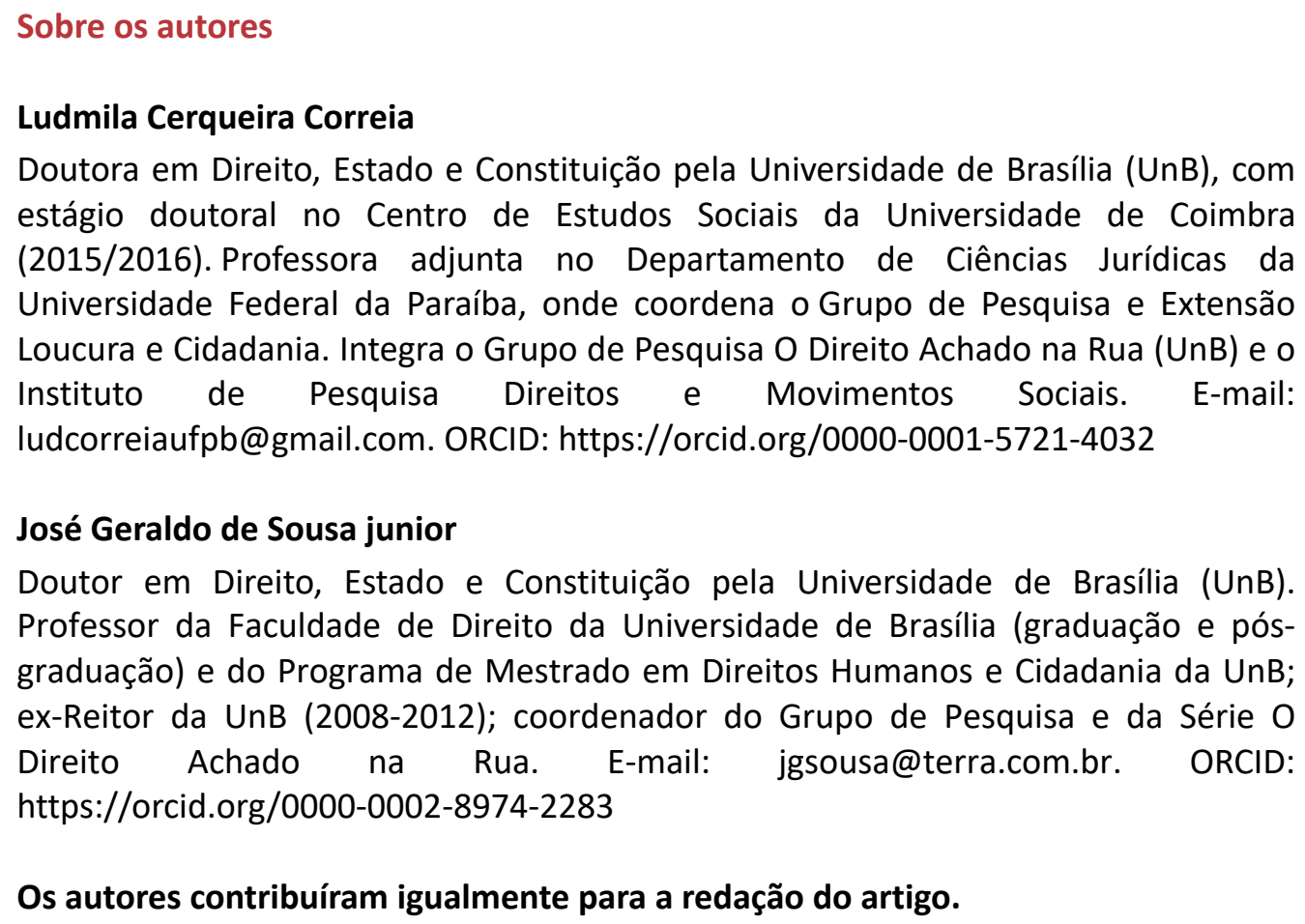

